\title{
Relation between periodontal disease and ischemic heart disease
}

\author{
Tanzir Hassan Siddiqui, Sohel Reza Choudhury, Mozammal Hossain and Lubna Khondker
}

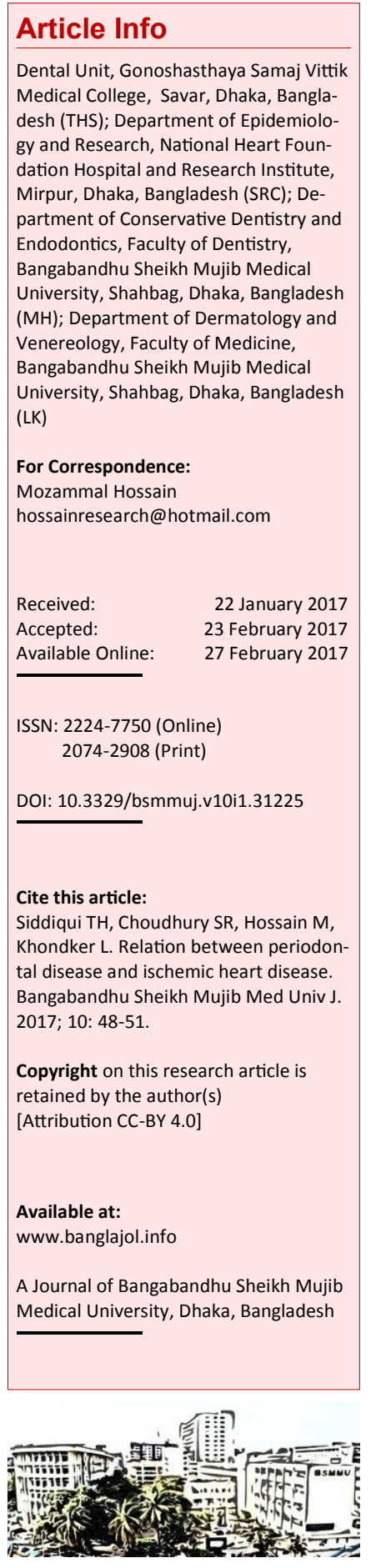

\section{Abstract}

The aim of this study was to determine the association between periodontal diseases and ischemic heart disease among 30 exercise tolerance test (ETT) positive and 30 ETT negative of ischemic heart disease patients attending the National Heart Foundation Hospital and Research Institute. The presence of gum swelling for the two groups were statistically significant. The results revealed that $80 \%$ ETT positive and $23 \%$ ETT negative respondent had gum bleeding, 53\% ETT positive and $7 \%$ ETT negative had ulceration of gingiva. Furthermore, severely inflamed with spontaneous bleeding was found in $53.3 \%$ ETT positive and $6.7 \%$ negative respondents. It can be concluded that oral hygiene should be promoted as a part of prevention of ischemic heart disease.

\section{Introduction}

Periodontal diseases promote increased blood viscosity and thrombogenesis, leading to an increased risk for the central and peripheral vascular disease. The prevalence in men between the age of 45 to 54 years is $2-5 \%$, and that of the age of 65 to 74 years is $11-20 \% .1$ The etiology and pathogenesis of periodontal diseases are multi-factorial and negatively influenced by a number of risk factors, such as smoking, stress, diabetes mellitus.-2-5 Consequently, both inflammatory periodontal disease and coronary heart disease are chronic diseases with similar etiological factors. Moreover, there is increasing evidence that poor oral hygiene and especially the presence of inflammatory periodontal disease increase the risk of coronary heart disease. On the basis of a number of studies, an association between chronic cardiovascular diseases (arteriosclerosis) and periodontal disease is likely..-9 There have also been an increasing number of reports of an association between periodontal inflammation and acute myocardial infarction. 10-16 However, the results of some other investigations have indicated that there is no association between coronary heart disease (and / or acute myocardial infarction) and periodontal disease. $\underline{.17-20}$

Periodontal conditions can be influenced by some systemic diseases and they also can act as risk factors for some other systemic disease. $\underline{21}$ Recent studies demonstrate that the association between oral health and atherosclerosis is consistent in different population samples and that the oral conditions precede coronary events. In moderate and advanced cases, the endotoxins (for example, LPS) of the microbial wall can stimulate the accumulation of plaque contributing to the formation of thrombi and

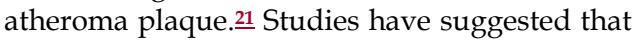
symptoms of poor oral health and periodontal disease can indicate ischemic heart disease events. $\underline{.2}$

The aim of this investigation was, therefore, to evaluate the state of oral health in patients with ETT positive and to compare this with that of ETT negative group.

\section{Materials and Methods}

This study was done in the National Heart Foundation Hospital and Research Institute, during the period of August to December, 2013. All consecutive adult participants coming to ETT examination were included in the study after meeting inclusion and exclusion criteria. All patients with ischemic heart disease who are willing to participate in this hospital were included. The participants were categorized into two groups such as ETT positive and ETT negative.

A total of 30 ETT positive and 30 ETT negative patients of ischemic heart disease were enrolled for the study. Among them $33.3 \%$ were in the age group of $40-49$ years. The mean age of the ETT positive participant were $52.8 \pm 9.8$ years and ETT negative subjects were $47.7 \pm 8.1$ years. Over all there were 48 men and 12 women were participating in the study.

After taking written informed consent to participate in the study the descriptive analyses 
of all of the variables were done such as frequency distribution of variables, cross tabulation among the variables and association of various factors was also done applying test of significance. Data processing and statistical analysis were done using software SPSS (Statistical Package for Social Science) version 16. Chi-square test was used to see the difference between the two groups for different indicators and level of significance was considered at 0.05 and $\mathrm{p}<0.05$ level was considered significant.

\section{Results}

Residential status of the ETT positive participants were $33 \%$ of rural and $67 \%$ of urban, whereas among the ETT negative, $23 \%$ were rural and $77 \%$ were urban. Among the ETT positive, 23.3\% were service holder and $43.3 \%$ were businessman; whereas among the ETT negative patients $43.3 \%$ were service holder and $36.7 \%$ were businessman. Furthermore, among the ETT positive, $47 \%$ were smokeless tobacco user and among the ETT negative, $20 \%$ were smokeless tobacco user.

\begin{tabular}{|c|c|c|c|c|}
\hline \multicolumn{5}{|c|}{ Table I } \\
\hline \multicolumn{5}{|c|}{ Results of clinical appearance of gingiva } \\
\hline & \multicolumn{2}{|c|}{ Exercise tolerance test } & \multirow[t]{2}{*}{ Total } & \multirow[t]{2}{*}{$\mathrm{p}$ value } \\
\hline & Positive & Negative & & \\
\hline Swelling of gum & $\begin{array}{r}25 \\
(83)\end{array}$ & $\begin{array}{r}16 \\
(53)\end{array}$ & $\begin{array}{r}41 \\
(68)\end{array}$ & 0.010 \\
\hline Gum bleeding & $\begin{array}{r}24 \\
(80)\end{array}$ & $\begin{array}{r}7 \\
(23)\end{array}$ & $\begin{array}{r}31 \\
(52)\end{array}$ & 0.000 \\
\hline Ulceration of the gingiva & $\begin{array}{r}16 \\
(53)\end{array}$ & $\begin{array}{r}2 \\
(7)\end{array}$ & $\begin{array}{r}18 \\
(30)\end{array}$ & 0.000 \\
\hline $\begin{array}{l}\text { Calculus along the gingival mar- } \\
\text { gin }\end{array}$ & $\begin{array}{r}26 \\
(87)\end{array}$ & $\begin{array}{r}7 \\
(23)\end{array}$ & $\begin{array}{r}45 \\
(75)\end{array}$ & 0.030 \\
\hline \multicolumn{5}{|l|}{ Plaque index } \\
\hline Normal & $\begin{array}{r}2 \\
(6.7)\end{array}$ & $\begin{array}{r}4 \\
(13.3)\end{array}$ & $\begin{array}{r}6 \\
(10)\end{array}$ & 0.004 \\
\hline Mild & $\begin{array}{r}12 \\
(40)\end{array}$ & $\begin{array}{r}22 \\
(73.3)\end{array}$ & $\begin{array}{r}34 \\
(56.7)\end{array}$ & 0.004 \\
\hline Moderate & $\begin{array}{r}16 \\
(53.3)\end{array}$ & $\begin{array}{r}3 \\
(10)\end{array}$ & $\begin{array}{r}19 \\
(31.7)\end{array}$ & 0.004 \\
\hline Severe & $\begin{array}{r}0 \\
(0.0)\end{array}$ & $\begin{array}{r}1 \\
(3.3)\end{array}$ & $\begin{array}{r}1 \\
(1.7)\end{array}$ & 0.004 \\
\hline \multicolumn{5}{|l|}{ Gingival Index } \\
\hline Normal & $\begin{array}{r}4 \\
(13.3)\end{array}$ & $\begin{array}{r}11 \\
(36.7)\end{array}$ & $\begin{array}{r}15 \\
(25)\end{array}$ & 0.000 \\
\hline $\begin{array}{l}\text { Mildly inflammed without } \\
\text { bleeding }\end{array}$ & $\begin{array}{r}2 \\
(6.7)\end{array}$ & $\begin{array}{r}12 \\
(40)\end{array}$ & $\begin{array}{r}14 \\
(23.3)\end{array}$ & 0.000 \\
\hline $\begin{array}{l}\text { Moderately inflammed with } \\
\text { bleeding }\end{array}$ & $\begin{array}{r}8 \\
(26.7)\end{array}$ & $\begin{array}{r}5 \\
(16.7)\end{array}$ & $\begin{array}{r}18 \\
(30)\end{array}$ & 0.000 \\
\hline $\begin{array}{l}\text { Severely inflammed with spon- } \\
\text { taneous bleeding }\end{array}$ & $\begin{array}{r}16 \\
(53.3)\end{array}$ & $\begin{array}{r}2 \\
(6.7)\end{array}$ & $\begin{array}{r}18 \\
(30)\end{array}$ & 0.000 \\
\hline
\end{tabular}

Data within the parenthesis are the percentage
There were significant changes in the swelling of gum, gum bleeding, ulceration and calculus in case of ETT positive patients in comparison to ETT negative one (Table I).

Table I also shows that regarding plaque index, $40 \%$ ETT positive respondents had mild and $53.3 \%$ had moderate plaque. Again regarding the gingival index, 53.3\% ETT positive respondent was severely inflammed with spontaneous bleeding and $6.7 \%$ of ETT negative was severely inflammed. The differences were statistically significant.

\section{Discussion}

In this study, patients with ischemic heart disease were taken in terms of age, gender and smoking behavior with a proven generally healthy group and studied with regard to their oral health status. The majority of participants in both groups showed good oral hygiene behavior and control oriented behavior in relation to the use of dental care and treatment. The total number of tooth loss the difference between the ETT positive group and ETT negative group was significant. In relation to oral hygiene practice and behavior, no difference was found between the two groups. In contrast, ischemic heart disease patients showed significantly more signs of gingival inflammation then the healthy subjects. Nevertheless, two-third of the ischemic heart disease-group and approximately one half of the healthy group had moderate to severe periodontitis.

The finding that the ischemic heart disease patients showed a higher rate of tooth loss then the healthy subjects confirmed some previous studies. $.22-23$ Other studies were unable to find a significant difference in the number of missing teeth.10,11,13,15 Moreover, a large prospective study in Sweden showed a close relationship between number of missing teeth and cardiovascular and coronary heart diseases (and even cardiovascular mortality), indicating a link between coronary artery disease and oral health. $\underline{24}$ One participant of each group was toothless.

Considering the results for periodontal index the differences between the groups were not significant, but oral hygiene in the ischemic heart disease-group tended to be worse. This finding has been obtained by two other studies. 15,25 In the case of ischemic heart disease patients, however, gingival inflammation was increased significantly versus healthy subjects. It should be taken into account that $18 \%$ of the ischemic heart disease patients in the studies mentioned above had diabetes mellitus, $\underline{25}$ and in addition, there were differences in smoking behavior between the ischemic heart disease patients and the control subjects.22,25 This could possibly have influenced (confounder) the results. In the present study, these factors were 
taken into account by procedure and exclusion criteria, and can be excluded as a possible confounder. Other research groups used other indices for assessing the state of gingival inflammation such as bleeding on probing. 26,27 they observed that the ischemic heart disease patients showed a worse gingival status than the control subjects. These findings could be confirmed by the results of this study. Only one investigation established no difference between the groups.20

In the present study, no difference was found between ischemic heart disease-group and healthy subjects with regard to the periodontal situation. However, two-third of the ischemic heart disease patients had an increased periodontal treatment need despite regular visits to the dentist. In contrast, Willershausen et al.28 found a significant higher amount of periodontal index score 4 in their ischemic heart disease patients, it is to mention that there were clearly (significant) more smokers and diabetics in their ischemic heart disease-group than in the corresponding control group. An association between moderate periodontitis and cardiac disease was likewise not found by this research group. $\underline{29}$ In contrast to this, some studies have indicated that in ischemic heart disease patients significantly more measurement points with increased probe depths of $>4$ or $>5 \mathrm{~mm}$ were present than in control subjects. $\underline{19}$

Likewise, in the present study, no statistically significant difference was found in relation to loss of attachment. In contrast to this, other studies showed a significant correlation between ischemic heart disease and an increased loss of attachment.22 A number of authors established a correlation between a poor state of oral hygiene and ischemic heart disease. Although the ischemic heart disease patients in this study had poor oral hygiene, the differences in relation to the healthy control group were marginal. Only in relation to signs of gingival inflammation there were significant differences.

\section{Conclusion}

There were significant positive associations between several indicators of oral health such as swelling of gum, gum bleeding, calculus along the gingival margin, ulceration of gingival, plaque index and loss of tooth with ischemic heart disease in patents attending the outpatient department of a cardiac care hospital.

\section{References}

1. The European Society of Cardiology. Guidelines: Management of the stable angina pectoris. Eur Heart J. 1997; 18: 394-413.
2. Page RC, Kornman KS. The pathogenesis of human periodontitis: An introduction. Periodontal 2000; 14: 9-11.

3. Heasman LSF, Preshaw PM, McCracken GI, et al. The effect of smoking on periodontal treatment response: A review of clinical evidence. J Clin Periodontal. 2006; 33: 241-53.

4. Genco RJ, Ho AW, Grossi SG, Dunford RG, Tedesco LA. Relationship of stress, Distress, and inadequate coping behaviors to periodontal disease. J Periodontal. 1999; 70: 711-23.

5. Mealey BL, Oates TW. Diabetes mellitus and periodontal diseases. J Periodontal. 2006; 77: 1289-1303.

6. Janket S, Baird AE, Chuang S, Jones JA. Meta analysis of periodontal disease and risk of coronary heart disease and stroke. Oral Surg Oral Med Oral Pathol Oral Radiol Endod. 2003; 95: 559-69.

7. Khader YS, Albashaireh ZS, Alomari MA. Periodontal diseases and the risk of coronary heart and cerebrovascular diseases: A meta-analysis. J Periodontal. 2004; 75: 1046-53.

8. Bahekar AA, Singh S, Saha S, Molnar J, Arora R. The prevalence and incidence of coronary heart disease is significantly increased in periodontitis: A meta-analysis. Am Heart J. 2007; 154: 830-37.

9. Friedewald VE, Kornman KS, Beck JD, Genco R, Goldfine A, Libby P, Offenbacher S, Ridker PM, Van Dyke TE, Roberts WC. The American Journal of Cardiology and Journal of Periodontology Editors' consensus: Periodontitis and atherosclerotic cardiovascular disease. J Periodontal. 2009; 80: 1021 -32 .

10. Emingil G, Buduneli E, Aliyev A, Akilli A, Atilla G. Association between periodontal disease and acute myocardial infarction. J Periodontal. 2000; 71: 188286.

11. Persson RG, Ohlsson O, Pettersson T, Renvert $S$. Chronic periodontitis, a significant relationship with acute myocardial infarction. Eur Heart J. 2003; 24: 2108-15.

12. Elter JR Champagne CM, Ofenbacher S, Beck JD. Relationship of periodontal disease and tooth loss to prevalence of coronary heart disease. J Periodontal. 2004; 75: 782-90.

13. Dogan B, Buduneli E, Emingil G, Akilli A, Antinheimo J, Lakio L, Asikainen S. Characteristics of periodontal microflora in acute myocardial infarction. J Periodontal. 2005; 76: 740-48.

14. Blaizot A, Vergnes JN, Nuwwareh S, Amar J, Sixou M. Periodontal diseases and cardiovascular events: Meta-analysis of observational studies. Int Dent J. 2009; 59: 197-209.

15. Stein JM, Kuch B, Conrads G, Fickl S, Chrobot J, Schulz S, Ocklenburg C, Smeets R. Clinical periodontal and microbiologic parameters in patients with acute myocardial infarction. J Periodontal. 
2009; 80: 1581-89.

16. Dorn JM, Genco RJ, Grossi SG, Falkner KL, Hovey KM, Iacoviello L, Trevisan M. Periodontal disease and recurrent cardiovascular events in survivors of myocardial infarction (MI): The Western New York Acute MI Study. J Periodontal. 2010; 81: 502-11.

17. Hujoel PP, Drangshot M, Splekerman C, DeRouen TA. Periodontal disease and coronary heart disease risk. JAMA. 2000; 284: 1406-10.

18. Hujoel PP, Drangshot M, Splekerman C, Derouen TA. Examining the link between coronary heart disease and the elimination of chronic dental infections. JADA. 2001; 132: 883-89.

19. Howell TH, Ridker PM, Ajani UA, Hennekens CH, Christen WG. Periodontal disease and risk of subsequent cardiovascular disease in U.S. male physicians. J Am Coll Cardiol. 2001; 37: 445-50.

20. Hung HC, Joshipura KJ, Colditz G, Manson JE, Rimm EB, Speizer FE, Willett WC. The association between tooth loss and coronary heart disease in men and women. J Public Health Dent. 2004; 64: 209-15.

21. Döring Y, Soehnlein O, Weber C. neutrophil extracellular traps in atherosclerosis and atherothrombosis. Circ Res. 2017; 120: 736-43.

22. Luis-Delgado O, Echevarria-Garïa JJ, Berini-Avtës L, Gay-Escoda C. Periodontitis as a risk factor in patients with ischemic heart disease. Med Oral. 2004; 9: 131-37.
23. Lopez R, Oyarzun M, Naranjo C, Cumsille F, Ortiz $\mathrm{M}$, Baelum V. Coronary heart disease and periodontitis: A case control study in Chilean adults. J Clin Periodontol. 2002; 29: 468-73.

24. Holmlund A, Holm G, Lind L. Number of teeth as a predictor of cardiovascular mortality in a cohort of 7,674 subjects followed for 12 years. J Periodontol. 2010; 81: 870-76.

25. Bazile A, Bissada NF, Nair R, Siegel BP. Periodontal assessment of patients undergoing angioplasty for treatment of coronary artery disease. J Periodontol. 2002; 73: 631-36.

26. Meurman JH, Qvarnstrom M, Janket S, Nuutinen P. Oral health and health behavior in patients referred for open-heart surgery. Oral Surg Oral Med Oral Pathol Oral Radiol Endod. 2003; 95: 300-07.

27. Mattila KJ, Asikainen S, Wolf J, Jousimies-Somer H, Valtonen V, Neiminen M. Age, dental infections and coronary heart disease. J Dent Res. 2000; 79: 756-60.

28. Willershausen B, Kasaj A, Willershausen I, Zahorka D, Briseno B, Blettner M, Genth-Zotz S, Munzel T. Association between chronic dental infection and acute myocardial infarction. J Endod. 2009; 35: 62630.

29. Katz J, Chaushu G, Sharabi Y. On the association between hypercholesterolemia, cardiovascular disease and severe periodontal disease. J Clin Periodontol. 2001; 28: 865-68. 